\title{
Detection of pathogenic Escherichia coli on potentially contaminated beef carcasses using cassette PCR and conventional PCR
}

\author{
Dammika P. Manage ${ }^{1}$, Jana Lauzon ${ }^{1}$, Christina M. Jones ${ }^{1}$, Patrick J. Ward ${ }^{2}$, Linda M. Pilarski ${ }^{1 \dagger}$,
} Patrick M. Pilarski ${ }^{3+}$ and Lynn M. McMullen ${ }^{2 *}$ (D)

\begin{abstract}
Background: Over a one year period, swabs of 820 beef carcasses were tested for the presence of Shiga toxinproducing Escherichia coli by performing Polymerase Chain Reaction (PCR) in a novel technology termed "cassette PCR", in comparison to conventional liquid PCR. Cassette PCR is inexpensive and ready-to-use. The operator need only add the sample and press "go". Cassette PCR can simultaneously test multiple samples for multiple targets. Carcass swab samples were first tested for the presence of STEC genes (O157, eae, stx1 and stx2). Samples were considered to be pathogenic if positive for eae plus st $\times 1$ and/or st $x 2$. For samples scored as pathogenic, further testing screened for 6 additional high frequency O-antigens (O26, O45, O103, O111, O121, and O145).
\end{abstract}

Results: Of the 820 samples, 41\% were pathogenic and 30\% were 0157 positive. Of these, 19\% of samples were positive for 0157 and carried potentially pathogenic E. coli (eae plus st $\times 1$ and/or stx2). Of all samples identified as carrying pathogenic E. coli, 18.9, 38.8, 41.4, 0,36.1, and 4.1\% respectively were positive for O26, O45, O103, O111, O121, and O145. To validate cassette PCR testing, conventional PCR using STEC primers was performed on each of the 820 samples. Only 148 of 3280 cassette PCR tests were discordant with conventional PCR results. However, further fractional testing showed that 110 of these 148 PCRs reflected low numbers of $E$. coli in the enrichment broth and could be explained as due to Poisson limiting dilution of the template, affecting both cassette PCR and conventional PCR. Of the remaining 38 discordant tests, 27 initial capillary PCRs and 10 initial conventional tests were nominally discordant between cassette and conventional PCR, perhaps reflecting human/technical error on both sides of the comparison.

Conclusions: Contaminated beef carcass swabs were often complex, likely harboring more than one strain of pathogenic E. coli. Cassette PCR had 98.8\% concordance with parallel conventional PCR for detection of STEC genes. This indicates that cassette PCR is highly reliable for detecting multiple pathogens in beef carcass swabs from processing plants.

Keywords: Cassette PCR, Validation study, Beef carcass swabs, STEC detection, O-antigen complexity

\section{Background}

Although different strains of Escherichia coli are naturally occurring in the digestive tract of ruminant animals including cattle, shiga toxin-producing E. coli (STEC) are harmful to humans $[1,2]$. Contamination of meat

\footnotetext{
* Correspondence: lynn.mcmullen@ualberta.ca

†Linda M. Pilarski, Patrick M. Pilarski and Lynn M. McMullen contributed equally to this work.

${ }^{2}$ Department of Agricultural, Food and Nutritional Science, University of Alberta, Edmonton, Alberta T6G 2P5, Canada

Full list of author information is available at the end of the article
}

with STEC strains can occur at during evisceration and harvest of meat, making it one of the most common causes of food-borne diseases. Recalls of contaminated meat cost food industries millions of dollars. Meat testing is routinely conducted in abattoirs to detect potential contamination. Most testing strategies are time consuming with over $18 \mathrm{~h}$ or longer to detect $1-3$ colonyforming units (cfu). Cassette PCR was developed to meet the need for simpler, cheaper and faster food testing [3] (Manage et al., in preparation).

(c) The Author(s). 2019 Open Access This article is distributed under the terms of the Creative Commons Attribution 4.0 International License (http://creativecommons.org/licenses/by/4.0/), which permits unrestricted use, distribution, and reproduction in any medium, provided you give appropriate credit to the original author(s) and the source, provide a link to the Creative Commons license, and indicate if changes were made. The Creative Commons Public Domain Dedication waiver (http://creativecommons.org/publicdomain/zero/1.0/) applies to the data made available in this article, unless otherwise stated. 
The most commonly identified cause of infection with STEC strains is that of the O157:H7 serotype. However, the infections due to non-O157 STEC serotypes are on the rise [4-7]. North American food agencies target non-O157 STEC belonging to serogroups O26, O45, O103, O111, O121, and O145. These six serotypes are believed to be causing more than $70 \%$ of non-O157 STEC infections in the USA [8]. The main virulence factors of STEC strains include the production of Shiga-toxin (Stx) 1 or 2 and intimin (eae), an adhesion molecule that ensures toxin-producing $E$. coli remain firmly attached to the intestine (ehxA) localizing high toxin levels that cause hemolytic disease [6]. A strain of E. coli is considered to be pathogenic if it carries genes for eae as well as stx 1 and/or st $x 2$. However, strains that carry only stx 2 are highly pathogenic [9], suggesting that other adhesion molecules can substitute for eae.

Current methods for detection of STEC strains involve culture-based methods, immunoassays, and DNA amplification methods, all of which require an enrichment procedure to increase the number of cells to a detectable level. Culture methods can be considered as the gold standard for detection of food-borne pathogens. However, their biggest drawback is the time required to obtain results, e.g. 24 to $48 \mathrm{~h}$. The most commonly used DNA amplification method, Polymerase Chain Reaction (PCR), copies the target DNA, using specific primer sets. Conventional PCR is performed in a thermocycler in liquid media and the products can be detected in a variety of ways. In agarose gel electrophoresis, the amplicons are visualized by adding a dye to the gel. Capillary electrophoresis identifies product size using fluorescence to detect products. Amplification can be measured in situ by monitoring accumulation of fluorescent products in real time, sometimes in combination with Melt Curve Analysis (MCA) to verify product identity; this is the method used for cassette PCR. MCA is based on measuring the DNA denaturation point $\left(\mathrm{T}_{\mathrm{m}}\right)$ that confirms product identity, based mainly on GC content and size of the amplicon.

Cassette PCR successfully detects pathogens and single nucleotide polymorphisms in raw body fluids or in food products [10-14]. PCR is performed in semi-solid gel, followed by in situ MCA in a capillary reaction unit ( $\sim 6 \mu \mathrm{L}$ volume) that contains all reagents, including a primer set and Taq polymerase, with arrays of capillaries assembled in each cassette. Each capillary contains only one primer set to detect one target. An array of capillaries, each with a different primer set, allows simultaneous detection of multiple targets in parallel. Cassettes can be assembled to detect the desired panel of targets. The sample is administered to the cassette via capillary forces with no pumps or applied pressure involved. The cassette geometry can be altered for the test requirement. These pre-made cassettes can be stored for at least 7 months at $4{ }^{\circ} \mathrm{C}$ or $-20^{\circ} \mathrm{C}[10]$ and up to 3 years at $4{ }^{\circ} \mathrm{C}$ (unpublished results). With this technology, we have previously detected multiple sexually transmitted diseases for multiple patients with raw urine and genital swabs [11] and single nucleotide polymorphisms in breast cancer genes tested using buccal swabs [12]. With a somewhat different architecture for making reaction gels, we also amplified BK virus in whole blood with no purification involved [13].

Over a one year period, 820 beef carcasses from provincially inspected processing plants in Alberta were swabbed to evaluate contamination with potentially pathogenic E. coli using two detection methods, cassette PCR and liquid tube-based PCR, here termed conventional PCR. Swabs were collected several times per week over a year, from January to December of 2016 from several small provincial abattoirs in Alberta, and processed by Alberta Agriculture and Forestry (AAF). An aliquot of each enriched sample was tested by cassette and conventional PCR. Cassette PCR was validated to be $98.8 \%$ concordant with conventional PCR. Analysis of STEC targets as well as $\mathrm{O}$-antigen genotypes indicated that carcass swab samples are highly complex, containing multiple strains of pathogenic E. coli. Pathogenicity, defined here as presence of eae plus stx 1 and/or stx2, was detected in $41 \%$ of swab samples. Either or both of $s t x 1$ and stx 2 was found in $58 \%$ of swab samples, with all Oantigens represented except $\mathrm{O} 111$.

\section{Results}

\section{Cassette PCR}

PCR was performed in the cassette containing 36 capillaries in 9 trenches where seven samples were tested in the first 7 trenches and negative and positive controls were tested in the last two trenches respectively for four STEC primer sets. Images taken after cycle 1 and cycle 35 of the PCR are shown in Fig. 1 for a STEC cassette.

Melt peaks of four different samples are shown in Fig. 2 representing some of the various patterns of STEC results observed in this study. Patterns of positivity vary from all four PCR reactions scoring positive to all four PCR reactions scoring negative.

The gel image in Fig. 2(g) shows the PCR products from the conventional PCRs run with four STEC primers corresponding to the samples in (a)-(f).

\section{STEC pathogen contamination in beef carcass swabs}

For 820 carcass swab samples, we analyzed cassette PCR results using all four primer sets (O157, eae, stx1, stx2). Analysis of cassette PCR results for stx 1 , stx2 and eae categorized 338 samples as "pathogenic" (eae and stx 1 and/or stx 2 positive), as shown in Table 1. As indicated 


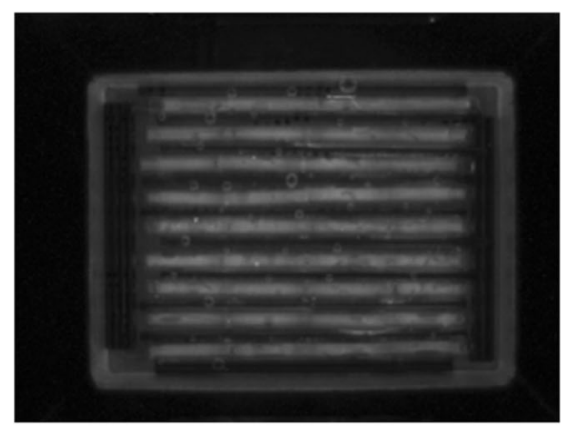

(a)

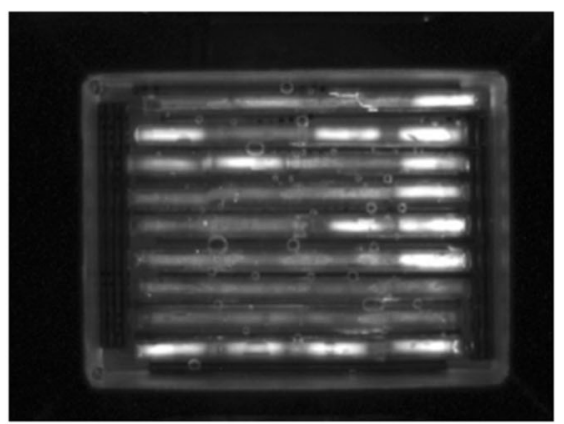

(b)

Fig. 1 CCD images of a cassette with 9 trenches and 4 sets of reaction units per trench (a) at 1st PCR cycle and (b) at 35th cycle. Four columns from left to right in 9 trenches (rows) have 0157, eae, stx 1 and stx 2 primers. The last trench (9th) has the positive control and 8 th trench has the negative control. Trenches $1-7$ have 7 carcass swab samples

below, the results from cassette PCR testing as shown in the Tables were concordant with parallel testing by conventional PCR.

For the 820 samples, 3280 individual PCRs were performed in cassette PCR and also in conventional PCR, with four STEC primers. In cassette PCR, 3132 reactions matched with conventional PCR. Only 148 reactions appeared to be non-concordant between the two methods. Some of the 148 out of 3280 reactions that did not match those for conventional PCR, or vice versa, gave weak peaks or bands, suggesting that template might be limiting and that a fractional analysis was required. These 148 PCRs were replicated 4-8 times in both cassette PCR and with conventional PCR in tubes (examples shown in Fig. 3).

About half of the 820 samples were positive for stx 2 (53\%) and slightly over a quarter of samples carried stx 1 (29\%) (Table 1). Of these, 70 and $79 \%$ of samples with stx 2 and stx 1 , respectively, carried eae, defining them as having pathogenic E. coli. A total of 30 and $21 \%$ of samples that were positive for stx 2 and stx 1 , respectively, lacked eae (Table 2), presumptively preventing them from adhering to the intestinal cells and thereby localizing toxin production.

For the 338 samples with a pathogenic genotype, a total of 2366 PCRs were performed using seven primer sets to detect the seven most frequent $\mathrm{O}$-antigens (Table 3).

As shown in Table 4, in the month of January, we performed the full panel of $\mathrm{O}$-antigen testing for all the samples irrespective of their pathogenicity. Enrichment broths from carcass swabs contained a complex mixture of strains of $E$. coli, including those lacking the seven most frequent $\mathrm{O}$-antigens.

To evaluate complexity of the $E$. coli strains in any given enrichment broth, we determined the number of $\mathrm{O}$-antigens that we present in the table. The presence or absence of genes for seven different $\mathrm{O}$-antigens were tested by PCR on the pathogenic samples. For any given sample, the number of detectable $\mathrm{O}$-antigens ranged from zero to 6 (O111 being absent from all samples tested). The number of $\mathrm{O}$-antigen genotypes present in each of the 338 pathogen-positive carcass swab samples are shown in Table 5.

\section{Discussion}

In summary, this analysis of carcass swabs demonstrated that they can carry complex mixtures of pathogenic $E$. coli. Individual swabs often harbored more than one strain of pathogenic E. coli. Analysis using a new testing technology, cassette PCR, indicated that cassette PCR had almost complete concordance with parallel conventional PCR for detection of STEC genes, indicating that cassette PCR is highly reliable for detecting multiple pathogens in beef carcass swabs from processing plants.

Cassette PCR was monitored via the increase in fluorescence of the LC Green dye, an intercalator that fluoresces only if bound to double stranded DNA [15]. As the PCR progresses by producing more and more double strand amplicons, the fluorescence increases. The fluorescent images of the cassette are taken by CCD camera during the PCR and MCA imaging all the capillaries at once.

As shown in the cassette image in Fig. 1(b), upon completion of PCR, there is an increase in fluorescence in some of the capillaries due to the double stranded DNA intercalated with LCGreen dye. When the temperature is raised during the MCA, double stranded DNA separates to single strands at the melting temperature of the PCR product causing the dye to disassociate, resulting in a sharp drop in the fluorescence. Plotting the first derivative of the fluorescence signal with the temperature produces a peak revealing the melt temperature of the product. Since this melting temperature is dependent on the GC content, length and the sequence of the product, it is possible to use it 


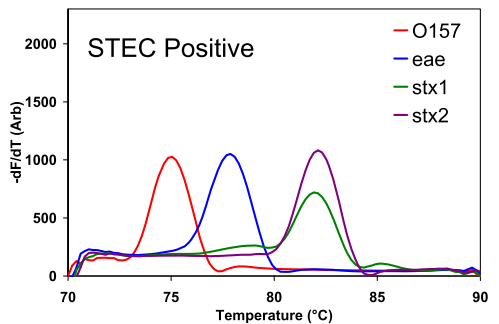

(a)

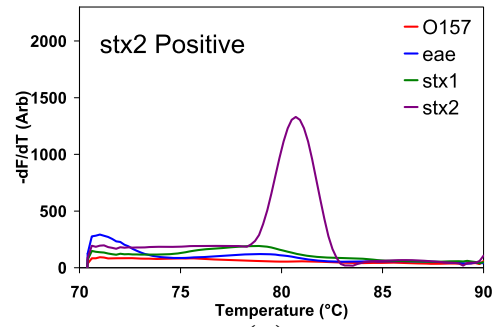

(c)

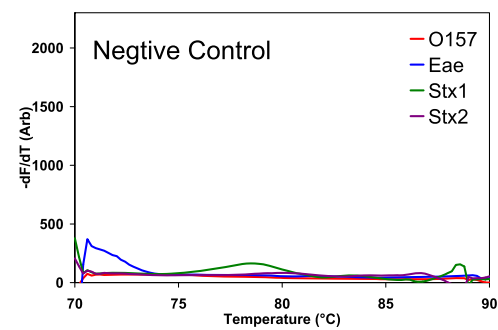

(e)

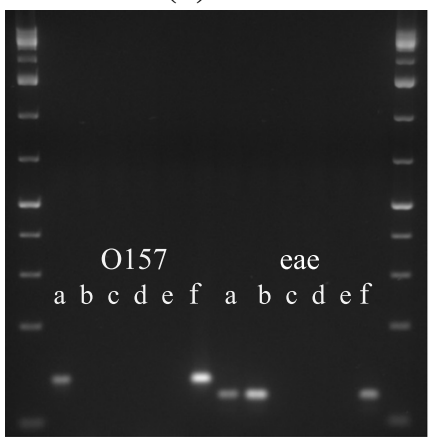

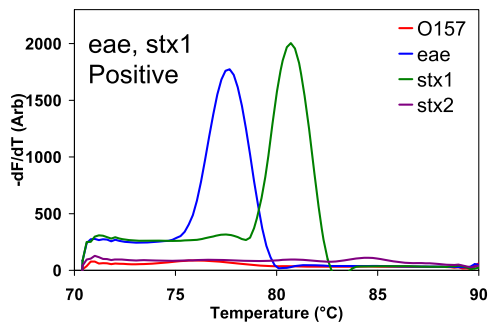

(b)

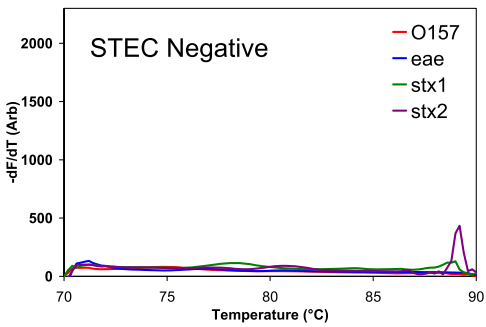

(d)

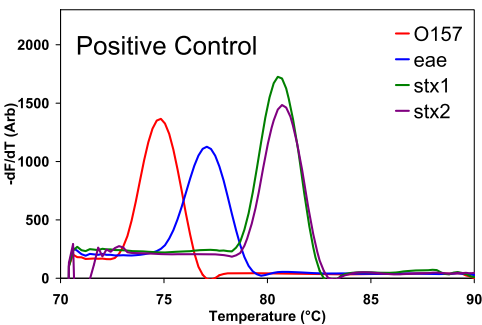

(f)

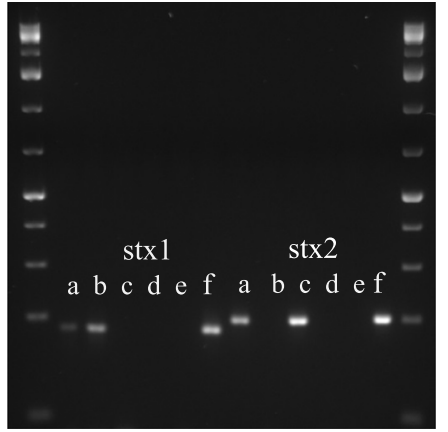

(g)

Fig. 2 Melt curve analysis data of the cassette for: four carcass swab samples; (a) a STEC positive; (b) positive for eae and stx1 only; (c) positive for stx2 only; (d) a STEC negative; and for (e) the negative control (water); (f) the positive control of the cassette; and (g) shows agarose gel images with the conventional PCR products of the same samples used in (a), (b), (c), and (d), as well as the controls used in (e) and (f). The ladder is GeneRuler $1 \mathrm{~kb}$ Plus DNA ladder (Themo Scientific, Carlsbad, USA)

as a marker to determine the PCR amplification of the correct target.

Therefore, the presence or the absence of a melt peak at the correct temperature in a given capillary with a given primer set determines the presence or absence of the target DNA template in any given sample. The temperature of the melt peak for a given primer was defined by the peak position for the positive control with the same primer set, with a tolerance of $\pm 1^{\circ} \mathrm{C}$. Peak intensity was determined as the extent to which a test peak rises above the intensity of the same primer in the negative control (water). Therefore, the positive peak is defined as a peak being at the correct temperature with an intensity above the background level. If such a peak is present in the MCA analysis, the PCR in the corresponding capillary is considered to be "positive". 
Table 1 The number and percentage of enrichment broths from carcass swab samples obtained from January to December, 2016 that were positive for STEC by cassette PCR

\begin{tabular}{|c|c|c|c|c|c|}
\hline \multirow[b]{2}{*}{ Month } & \multirow[b]{2}{*}{ total \# samples } & \multicolumn{4}{|c|}{ Number and percent (in brackets) of samples scoring positive } \\
\hline & & eae plus stx 1 and/or stx2 & stxl & $s t \times 2$ & Both $s t \times 1$ and $s t \times 2$ \\
\hline January & 42 & $18(42.9)$ & $9(21.4)$ & $25(59.5)$ & $9(21.4)$ \\
\hline February & 42 & $18(42.9)$ & $15(35.7)$ & $24(57.1)$ & $11(26.2)$ \\
\hline March & 64 & $26(40.6)$ & $16(25.0)$ & $35(54.7)$ & $13(20.3)$ \\
\hline April & 88 & $23(26.1)$ & $20(22.7)$ & $38(43.2)$ & $13(14.8)$ \\
\hline May & 56 & $28(50.0)$ & $20(35.7)$ & $32(57.1)$ & $16(28.6)$ \\
\hline June & 52 & $36(69.2)$ & $17(32.7)$ & $30(57.7)$ & $8(15.4)$ \\
\hline July & 56 & $42(75.0)$ & $32(57.1)$ & 39 (69.6) & $26(46.4)$ \\
\hline August & 44 & 16 (36.4) & $7(15.9)$ & $19(43.2)$ & $7(15.9)$ \\
\hline September & 72 & 37 (51.4) & $24(33.3)$ & $44(61.1)$ & 22 (30.6) \\
\hline October & 62 & 21 (33.9) & $11(17.7)$ & $33(53.2)$ & $10(16.1)$ \\
\hline November & 134 & 49 (36.6) & $43(32.1)$ & $74(55.2)$ & 37 (27.6) \\
\hline December & 108 & $24(22.2)$ & $23(21.3)$ & $38(35.2)$ & $16(14.8)$ \\
\hline Total & 820 & $338(41.2)$ & 237 (28.9) & 431 (52.6) & $188(22.9)$ \\
\hline
\end{tabular}

Concordance between the cassette PCR and conventional PCR

Comparison of the MCA results from 3280 individual capillaries with individual conventional PCRs revealed that only 148 reactions are non-concordant. As shown in Fig. 3, templates of some of these 148 samples might be limited. Fractional analysis revealed that 110 samples had results expected for a Poisson limiting dilution pattern where the template copy number is limiting. This indicates that cassette and conventional PCR were in fact concordant for these samples, both showing limiting dilution effects. For a further 27 out of 3280 cassette PCR tests and 10 conventional PCR tests, the initial results could not be repeated. These tests most probably reflect human or technical error. One sample repeated the original data even with replicates. However,

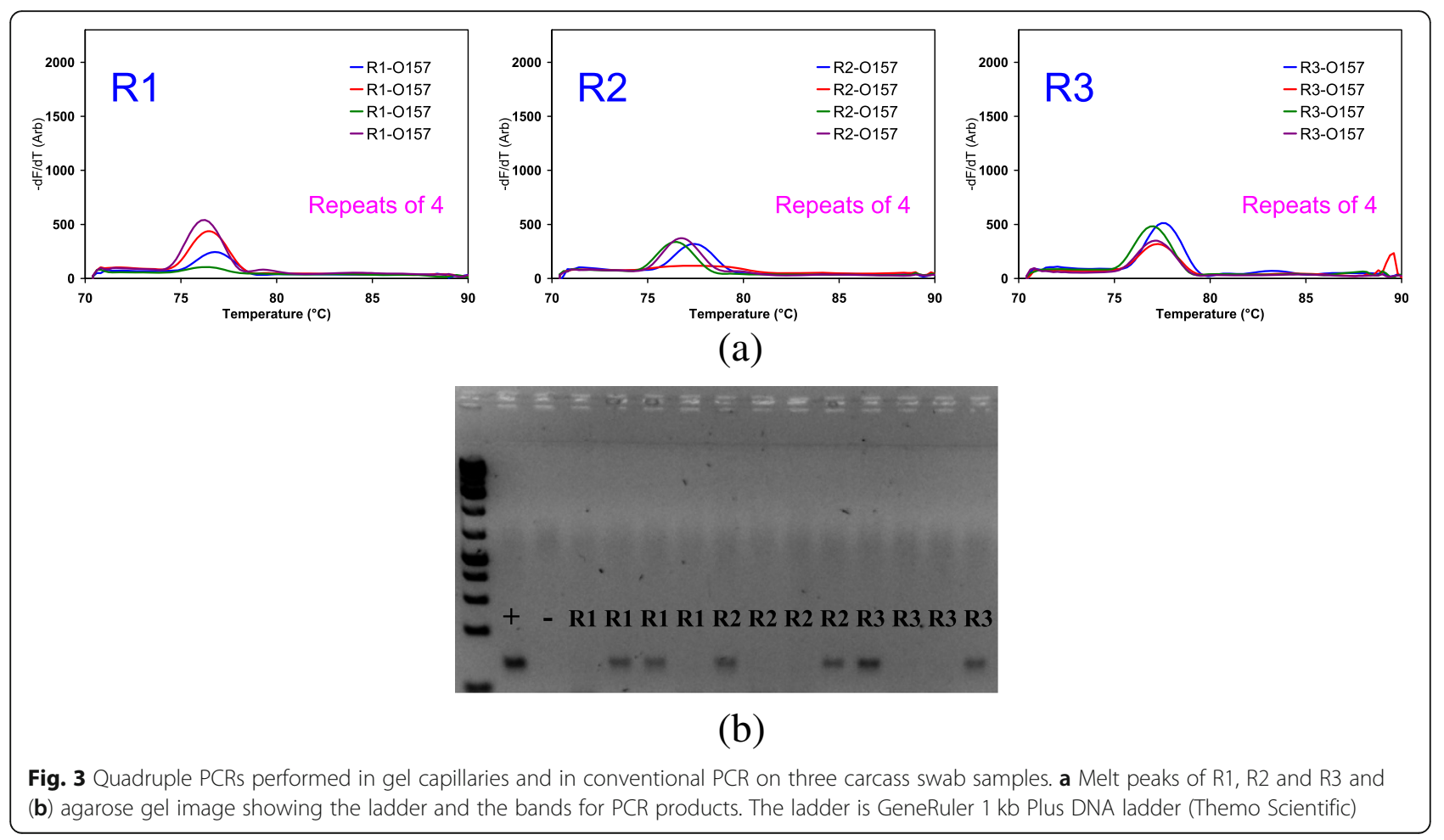


Table 2 Number and percentage (in brackets) of enrichment broths from carcass swab samples that were positive for stx 1 and/or stx2 but lacked eae. Data is from cassette PCR results

\begin{tabular}{|c|c|c|c|c|c|c|c|}
\hline Month & total \# samples & stx $1+$ ve & $\begin{array}{l}\text { stx } 1+\text { ve } \\
\text { but eae-ve }\end{array}$ & st $x 2+v e$ & stx $2+$ ve but eae $-v e$ & stx $1 \& 2+v e$ & $\begin{array}{l}\text { stx } 1 \& 2+v e \\
\text { but eae -ve }\end{array}$ \\
\hline January & 42 & 9 & $3(33.3)$ & 25 & $7(28.0)$ & 9 & $3(33.3)$ \\
\hline February & 42 & 15 & $3(20.0)$ & 24 & $8(33.3)$ & 11 & $1(9.1)$ \\
\hline March & 64 & 16 & $3(18.8)$ & 35 & $12(34.3)$ & 13 & $3(23.1)$ \\
\hline April & 88 & 20 & $10(50.0)$ & 38 & $18(47.4)$ & 13 & $6(46.2)$ \\
\hline May & 56 & 20 & $1(5.0)$ & 32 & $8(25.0)$ & 16 & $1(6.3)$ \\
\hline June & 52 & 17 & $1(5.9)$ & 30 & $2(6.7)$ & 8 & $0(0)$ \\
\hline July & 56 & 32 & $0(0)$ & 39 & $3(7.7)$ & 26 & $0(0)$ \\
\hline August & 44 & 7 & $1(14.3)$ & 19 & $3(15.8)$ & 7 & $1(14.3)$ \\
\hline September & 72 & 24 & $3(12.5)$ & 44 & $9(20.5)$ & 22 & $3(13.6)$ \\
\hline October & 62 & 11 & $4(36.4)$ & 33 & $13(39.4)$ & 10 & $4(40.0)$ \\
\hline November & 134 & 43 & $11(25.6)$ & 74 & $28(37.8)$ & 37 & $8(21.6)$ \\
\hline December & 108 & 23 & $9(39.1)$ & 38 & $19(50.0)$ & 16 & $7(43.8)$ \\
\hline Total & 820 & 237 & 49 (20.7) & 431 & $130(30.2)$ & 188 & 37 (19.7) \\
\hline
\end{tabular}

if we arbitrarily classify these as non-concordant samples, this shows that for cassette PCR, $98.8 \%$ of tests were concordant between cassette and conventional PCR for the same samples. Thus, for cassette PCR, 1.2\% of reactions appear to be nominally non-concordant in presumed process errors that affected conventional PCR as well as cassette PCR.

Even after nearly $20 \mathrm{~h}$ of enrichment, 110 PCRs had limiting copy numbers. Figure 3 shows quadruple PCRs run with the $\mathrm{O} 157$ primer set for three samples where cassette and conventional PCR gave different results that were resolved using fractional analysis. It should be noted that the amount of sample added in both to the capillary and to the conventional PCR is approximately the same $(\sim 6 \mu \mathrm{L}$ per reaction unit or tube). R1, R2, and R3 samples were positive for cassette PCR 3/4, 3/4, 4/4 replicates for each sample, respectively, while $2 / 4,2 / 4$, and $2 / 4$ were positive for conventional PCR, respectively, both showing the effects of a limiting dilution.

The swab samples used here were biologically complex samples with multiple species including microflora. During the enrichment, these multiple strains/species of $E$. coli and other bacteria would compete for nutrients for growth. Valadez et. al. showed that the presence of multiple strains with different $\mathrm{O}$-antigens added together in low numbers caused some not to grow [16]. When

Table 3 O-antigen genotypes in samples scoring positive for pathogenic E. coli, from January to December 2016. Data is from cassette PCR results

\begin{tabular}{|c|c|c|c|c|c|c|c|c|}
\hline \multirow[b]{2}{*}{ Month } & \multirow[b]{2}{*}{ total \# pathogen+ samples } & \multicolumn{7}{|c|}{ Number and percent (in brackets) of pathogen-positive samples } \\
\hline & & $\overline{\mathrm{O} 26}$ & $\mathrm{O} 45$ & 0103 & 0111 & 0121 & 0145 & 0157 \\
\hline January & 18 & $1(5.6)$ & $5(27.8)$ & $11(61.1)$ & $0(0)$ & $0(0)$ & $0(0)$ & $3(16.7)$ \\
\hline February & 18 & $1(5.6)$ & $5(27.8)$ & $8(44.4)$ & $0(0)$ & $0(0)$ & $1(5.6)$ & $4(22.2)$ \\
\hline March & 26 & $2(7.7)$ & $6(23.1)$ & $5(19.2)$ & $0(0)$ & $6(23.1)$ & $0(0)$ & $6(23.1)$ \\
\hline April & 23 & $1(4.3)$ & $6(26.1)$ & $4(17.4)$ & $0(0)$ & $6(26.1)$ & $0(0)$ & $6(26.1)$ \\
\hline May & 28 & $1(3.6)$ & 19 (67.9) & $13(46.4)$ & $0(0)$ & $13(46.4)$ & $2(7.1)$ & 11 (39.3) \\
\hline June & 36 & 11 (30.6) & 19 (52.8) & $22(61.1)$ & $0(0)$ & 14 (38.9) & $2(5.6)$ & $16(44.4)$ \\
\hline July & 42 & $23(54.8)$ & $19(45.2)$ & $29(69.0)$ & $0(0)$ & $28(66.7)$ & $1(2.4)$ & $27(64.3)$ \\
\hline August & 16 & $6(37.5)$ & $9(56.3)$ & $12(75.0)$ & $0(0)$ & $13(81.3)$ & $0(0)$ & $13(81.3)$ \\
\hline September & 37 & 7 (18.9) & $16(43.2)$ & $16(43.2)$ & $0(0)$ & $13(35.1)$ & $1(2.7)$ & $28(75.7)$ \\
\hline October & 21 & $2(9.5)$ & $10(47.6)$ & $4(19.0)$ & $0(0)$ & $5(23.8)$ & $0(0)$ & $12(57.1)$ \\
\hline November & 49 & $5(10.2)$ & $11(22.4)$ & $6(12.2)$ & $0(0)$ & 18 (36.7) & $1(2.0)$ & $24(49.9)$ \\
\hline December & 24 & $4(16.7)$ & $6(25.0)$ & $10(41.7)$ & $0(0)$ & $6(25.0)$ & $6(25.0)$ & $8(33.3)$ \\
\hline Total & 338 & 64 (18.9) & $131(38.8)$ & $140(41.4)$ & $0(0)$ & $122(36.1)$ & $14(4.1)$ & 158 (46.7) \\
\hline
\end{tabular}


Table 4 Results for the presence of O-antigens in enrichment broths received in the month of January

\begin{tabular}{lcccccccc}
\hline & \# of samples negative for O-antigens & \multicolumn{2}{l}{ \# of samples positive for O-antigens } \\
\cline { 3 - 8 } & & O26 & O45 & O103 & O111 & 0121 & 0145 & 0157 \\
\hline Non-pathogenic samples $(n=24)$ & 3 & 0 & 4 & 6 & 0 & 1 & 0 & 0 \\
Pathogen+samples $(n=18)$ & 3 & 1 & 5 & 11 & 0 & 0 & 0 & 3 \\
\hline
\end{tabular}

cultures were enriched individually with similar numbers, they were able to grow. In the current study, the swabs and enrichment broths may contain varying amounts of blood and other biological matter that could be inhibitory to the PCR. Competition among the microbiota and the presence of inhibitors may explain the weaker PCRs even after the samples were enriched for a considerable time.

Over the year long study of carcass swabs, we found that during the summer months nearly all samples carrying st $x 1$ and/or st 2 also carried eae, defining them as harboring pathogenic E. coli. Though these are the two primary types of Shiga toxin, the stx 2 gene has been identified as a high risk factor for bloody diarrhea and haemolytic uremic syndrome $[9,17]$, even when eae is absent, perhaps reflecting the contributions of adhesion molecules other than intimin. Co-expression of $s t x 1$ and $s t \times 2$ may result in reduced toxicity compared to expression solely of $s t x 2$, although differences in serotype or host background are also likely to influence pathogenicity [18]. However, in carcass swab samples it is not possible to confirm that $s t x 1$ and stx 2 are carried by the same cell for cases where both scored positive in testing.

\section{More frequent $\mathrm{O}$-antigens detected in carcass swab samples}

For the seven $\mathrm{O}$-antigens included in our screening, all were detected except O111. All primer sets were verified as accurate in cassette PCR by testing with known strains of E. coli. Other than for O157, O antigen status was not tested using conventional PCR. Testing for O157 by cassette and conventional PCR was concordant.

In contrast to the six non-O157 O-antigens that were tested only among enrichment broths shown to carry pathogenic E. coli, all 820 broths were tested for presence of O157, as part of the STEC panel of O157, eae, stx 1 and stx 2 primer sets. In 820 samples, 245 enrichment broths had O157, and 158 (64.5\%) of these also carry pathogenic E. coli. This indicated that $\mathrm{O} 157$ is present even in the apparent absence of eae and stx genes. However, among those $\mathrm{O} 157$ positive samples that lacked eae, 25/87 (29\%) did score positive for stx2, a genotype known to cause severe symptoms even when eae is absent [9].

Among the total of 42 samples tested for a full panel of O-antigens (for the month of January), only 36\% had a detectable $\mathrm{O}$-antigen as well as the markers for pathogenicity (eae and $s t x$ ). However, $26 \%$ carried a detectable $\mathrm{O}$-antigen even though they lacked a detectable STEC genotype. Thus, O-antigen positivity cannot be considered by itself to denote pathogenicity. Never the less, among the apparent pathogen-negative but $\mathrm{O}$-antigenpositive samples, 5/11 (45\%) did harbor stx2.

Overall, of the 338 pathogen-positive samples tested, when the number of $\mathrm{O}$-antigens in a given sample increases to $>1$, that sample tended to also carry O157. Of 338 enrichment broths scoring positive for eae and stx 1 and/or stx2 (termed pathogenic) tested for O-antigen genotypes, 186 (55\%) carried two or more $\mathrm{O}$-antigens, demonstrating the potential for the presence of more than one strain of pathogenic $E$. coli (Table 5). This highlighted the extensive complexity of $E$. coli populations in processing plant swabs. Significantly, $15 \%$ of pathogenic swab samples lacked any of the 7 major $\mathrm{O}$-antigen strains, suggesting that they carried rare $\mathrm{O}$-antigens. Of the pathogen-positive samples, 9\% carried only O157, again confirming the complexity of the swabs and the observation that O157 tends to be present together with other Oantigen strains of $E$. coli. The majority of samples that are O157-negative also lack any of the other major $\mathrm{O}$-antigens, indicating the pathogenic E. coli present in these samples must carry unknown O-antigen genotypes.

Foodborne outbreaks caused by non-O157 serotypes in the world, up to 2004 and in the USA up to 2010, were summarized by Bettelheim [5] and Luna-Gierke et. al. respectively [19]. Luna-Gierke et. al. reported 46

Table 5 Complex mixtures of E. coli strains with more than one O-antigen strain per sample

\begin{tabular}{|c|c|c|c|c|c|c|c|c|}
\hline & \multicolumn{8}{|c|}{ \# of different O-antigens in a given sample } \\
\hline & 1 & 2 & 3 & 4 & 5 & 6 & 7 & None \\
\hline \# of pathogenic samples & 100 & 87 & 54 & 34 & 9 & 2 & 0 & 52 \\
\hline$\%$ in pathogenic samples $(n=338)$ & 29 & 26 & 16 & 10 & 3 & 2 & 0 & 15 \\
\hline$\%$ of $0157+$ pathogenic samples $(n=158)$ & 20 & 27 & 27 & 20 & 6 & 1 & 0 & 0 \\
\hline
\end{tabular}


outbreaks in the USA, with 1727 illnesses and 144 hospitalizations. For outbreaks where the pathogen could be confirmed, over half involved STEC O111 or O26. The rest included small numbers of O45, O103, O121, O145, O104, O165, and $\mathrm{O}$ undetermined. Although O111 was the most common antigen in American outbreaks until 2010, surprisingly, we did not detect any O111 among our 820 samples. In Ontario, Bannon et al. found that O103, O45 and O121 were the most common strains identified on carcasses and the plant environment, but all six serotypes were represented [20]. The deadly 2011 outbreak in Germany was attributed to non-O157 strains, specifically to O104:H4 [18]. Considering the number of illnesses reported with non-O157 infections, together with our data showing the presence of carcasslocalized strains lacking any of the most frequent $\mathrm{O}$ antigens (Table 5), raises the issue of whether or not $\mathrm{O}$ antigen testing has value for food safety screening. A significant number of pathogenic $E$. coli may be missed if the focus is primarily on $\mathrm{O}$-antigen screening.

This analysis of samples collected over a full year shows that there was an increase in pathogen levels during the summer. This has been observed previously when detecting STEC in cattle feces samples collected during Jan-Mar and June-Aug from 24 pen floors [21]: O45, O111, and O121 were not detected during the summer months. In contrast, we detected more O-antigens during the summer months for all detected O-antigens, including O157, except for O145. Venegas-Vargas et. al studied the shedding of STEC pathogens in 1,096 cattle from six dairy and five beef herds in the summers of 2011 and 2012 . They found that the STEC pathogen shedding frequencies vary considerably across cattle herds in Michigan and shedding of non-O157 serotypes far exceeds shedding frequencies of O157, which is congruent with human infections in the state.

\section{Conclusions}

Cassette PCR used in this study for screening 820 carcass swab samples had $98.8 \%$ concordance with parallel conventional PCR testing of the same samples. We show that about $41 \%$ of beef carcass swabs carry pathogenic markers of eae plus stx1 and/or $s t x 2$. Carcass swab samples harbor complex mixtures of $E$. coli strains with as many as six different $\mathrm{O}$ antigens detectable in a single swab sample. In addition, a substantial proportion of swab samples lacked any of the most frequent $\mathrm{O}$-antigens, indicating that testing solely for $\mathrm{O}$-antigens, which do not play a major role in pathogenicity, is likely to miss some pathogenic strains. Testing for eae and stx genes, the mediators of pathogenicity, is essential for maintaining food safety. Cassette PCR, a simple, inexpensive and automated platform to screen food for its safety, contains capillary reaction units holding all the reagents needed for PCR except the sample. Each cassette can test multiple samples for multiple pathogens, including positive and negative controls for each cassette. Since the sample is delivered via capillary forces with no complex methods involved, relatively unskilled personnel can load the cassette and run the PCR while still ensuring accurate results. With this large number of samples and even larger number of individual tests, our validation data set showing $98.8 \%$ concordance with the conventional standard PCR tests confirms the reliability of the ready-to-use cassette PCR for detecting pathogens in food.

\section{Materials and methods \\ Samples}

Carcass sponge swabs were collected from provinciallylicensed abattoirs in Alberta during January - December 2016 by AAF. Sponge samples were enriched at $42{ }^{\circ} \mathrm{C}$ for $15-24 \mathrm{~h}$ in modified Tryptic Soy Broth (mTSB, OXOID, Basingstoke, England). Aliquots of the enriched media were provided for testing by cassette and conventional PCR. A total of 82 batches of enriched samples were received from AAF; the number of samples varied from 2 to 26 samples per batch. With each batch of samples, a sterility control (enriched uninoculated media), a positive control (enriched E. coli O157:H7 ATCC 35150), and a negative control (enriched media with E. coli ATCC 25922) were provided by AAF. For processing, $8 \mu \mathrm{L}$ of the enriched sample was added to $72 \mu \mathrm{L}$ of a proprietary buffer (Amplicet Inc., Edmonton $\mathrm{AB}$, Canada). This mix was heated at $55^{\circ} \mathrm{C}$ for $15 \mathrm{~min}$ and then to $97^{\circ} \mathrm{C}$ for $4 \mathrm{~min}$. The freshly processed sample was then used to rehydrate the capillary reaction units: $25 \mu \mathrm{l}$ was delivered per trench containing 4 capillary reaction units.

\section{Cassette PCR}

The sequences of the primers used to detect STEC and O-antigens are shown in Table 6. Separate reaction mixes were prepared with each of these primer sets to fill separate capillaries. Each $100 \mu \mathrm{L}$ reaction mix consisted of $20 \mu \mathrm{L}$ of $5 \mathrm{xPCR}$ buffer [333 mmol/L tris sulfate, $\mathrm{pH}$ 8.6, $83 \mathrm{mmol} / \mathrm{L}(\mathrm{NH} 4)_{2} \mathrm{SO}_{4}$ (Sigma, St. Louis, USA) and $40 \%$ sucrose (Sigma)], $30 \mu \mathrm{L}$ of $40 \%$ trehalose (Cargill Inc., Winnipeg, Canada), $4 \mu \mathrm{L}$ of $50 \mathrm{mmol} / \mathrm{L} \mathrm{MgCl}_{2}$ (Fluka, Buchs, Switzerland), $2 \mu \mathrm{L}$ of $10 \mathrm{mmol} / \mathrm{L}$ dNTP (Sigma), $2 \mu \mathrm{L}$ of $1 \%$ bovine serum albumin (Sigma), $4 \mu \mathrm{L}$ of $10 \mu \mathrm{M}$ primer solution for O157, stx1 and stx2, and $6 \mu \mathrm{L}$ of $10 \mu \mathrm{M}$ primer solution for eae (Integrated DNA Technologies, San Diego, USA), $10 \mu \mathrm{L}$ of 10x LC Green Plus (Idaho Technology Inc., Salt Lake City, USA), $4 \mu \mathrm{L}$ 
Table 6 Primer sequences for STEC and O-antigen amplifications

\begin{tabular}{|c|c|c|c|}
\hline Primer Name & Sequence & Length (bp) & Reference \\
\hline O157-F & TCG TGA CAA CCA TTC CAC CTT & 123 & This work \\
\hline O157-R & GCG CTG AAG CCT TTG GTT CT & & \\
\hline eae-F & CAT TGA TCA GGA TIT TTC TGG TGA TA & 102 & {$[22,23]$} \\
\hline eae- $R$ & CTC ATG CGG AAA TAG CCG TTA & & \\
\hline stx $1-\mathrm{F}$ & GTG GCA AGA GCG ATG TTA CGG TाT G & 182 & [24] \\
\hline stx1-R & ATG ATA GTC AGG CAG GAC GCT ACT C & & \\
\hline st $\times 2-F$ & ACG AGG GCT TGA TGT CTA TCA GGC G & 200 & [24] \\
\hline$s t \times 2-R$ & GCG ACA CGT TGC AGA GTG GTA TAA C & & \\
\hline O26-F & GTA TCG CTG AAA TTA GAA GCG C & 158 & {$[23,25]$} \\
\hline $\mathrm{O} 26-\mathrm{R}$ & AGT TGA AAC ACC CGT AAT GGC & & \\
\hline O45-F & TAT GAC AGG CAC ATG GAT CTG TGG & 132 & [26] \\
\hline $\mathrm{O} 45-\mathrm{R}$ & CAC AAC GCA ACG AAA GTC CC & & [27] \\
\hline O103-F & AAT TGC TCT ATG CGC TCT TCC & 136 & This work \\
\hline O103-R & GCC CAC CAT AGA TAA CAA CGA & & \\
\hline O111-F & GGA ATA ATC GAC CGG CCA AA & 199 & This work \\
\hline O111-R & TAA TGT GTT GCC TCG CCT TC & & \\
\hline O121-F & TGT TGG CTA GTG GCA TTC TGA & 212 & This work \\
\hline O121-R & TTC TGC ATC ACC AGT CCA GA & & [26] \\
\hline O145-F & AAA CTG GGA TTG GAC GTG G & 135 & [25] \\
\hline O145-R & CCC AAA ACT TCT AGG CCC G & & \\
\hline
\end{tabular}

of $20 \mathrm{U} / \mathrm{mL}$ Taq polymerase, $10 \mu \mathrm{L}$ of a $40 \%$ acrylamide (Sigma) $+4 \%$ bis-acrylamide aqueous solution (N,Nmethylene bisacrylamide; Bio-Rad, Hercules, USA), $2 \mu \mathrm{L}$ of $3 \%$ azobis (Wako Bioproducts, Richmond, USA), $1 \mu \mathrm{L}$ of $10 \% \mathrm{~N}, \mathrm{~N}, \mathrm{~N}^{\prime}, \mathrm{N}^{\prime}$ tetramethylethylenediamine (Sigma), and water. The mixes were vortexed, centrifuged, and loaded into the capillaries.

\section{Cassette preparation}

The method for constructing capillaries was published previously in detail [14]. Briefly, glass capillaries (with
$1.1 \mathrm{~mm}$ inner diameter) were custom cut to $6 \mathrm{~mm}$ pieces, heated to $550{ }^{\circ} \mathrm{C}$ overnight to remove any precoating, filled with reaction/gel mix, polymerized for 30 min under $370 \mathrm{~nm}$ wavelength, and desiccated overnight at a pressure of $81.27 \mathrm{~Pa}$. After desiccation, capillaries hold dried gel in the shape of a "noodle" (Fig. 4a). For delivering the sample to the capillary, the noodle shape of the dried gel is vital as the space created between the gel noodle and the glass capillary walls creates a path for the sample to flow by capillary force and thereby rehydrate the gel.

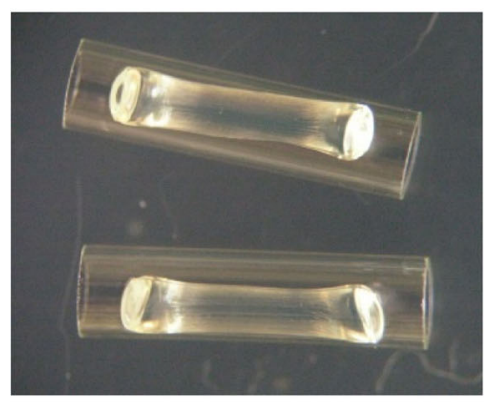

(a)

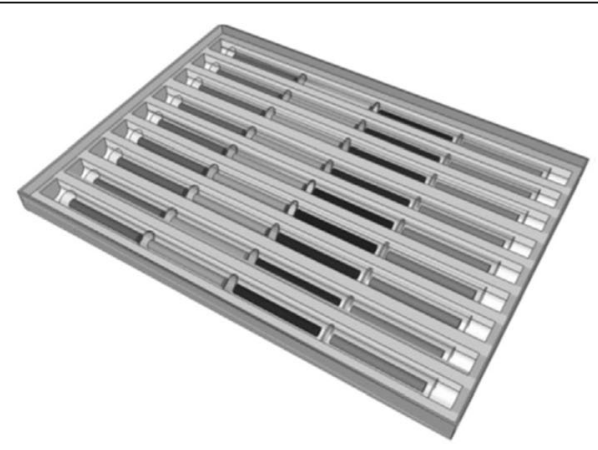

(b)

Fig. 4 Reaction capillaries and an assembled cassette for cassette PCR (a) Photograph of capillaries with dried gel inside. (b) Pan with a $4 \times 9$ capillary array ready-to-use cassette for STEC testing 
For laying capillaries, trench imprints were made in an aluminum pan $(23.5 \mathrm{~mm} \times 32 \mathrm{~mm})$ filled with $1 \mathrm{~mL}$ of wax (Surgipath Paraplast X-tra; Leica Microsystems, Deerfield, USA) with a polydimethylsiloxane stamp by heating wax to its melting temperature of $56^{\circ} \mathrm{C}$, as previously described $[11,14]$. The shape of the bottom of the trench has a curvature similar to that of the capillary, such that the capillary fits snugly in the wax trench. The capillaries with desiccated gels were placed in each trench of a pan with nine trenches. An example of a STEC cassette is shown in Fig. 4b. It contains 9 trenches where 7 trenches are used to test 7 samples while the last two trenches are used as integrated negative and positive controls for each cassette. Once the wax is melted, the liquid wax covers the capillaries and acts as a vapor barrier. For testing the six $\mathrm{O}$-antigens, three capillaries (O26, O45, and O103) were placed in one trench while the other three capillaries (O111, O121, and O145) were placed in the second trench. Nine trench cassettes can test 2 samples for O-antigens with 4 trenches reserved for positive and negative controls. When testing many samples for O-antigens, two separate pans were made, each testing three antigens per trench. This allows testing for $\mathrm{O}$-antigens of up to 7 samples with controls in two pans.

\section{Sample delivery}

The processed sample $(25 \mu \mathrm{L})$ was administered into the 1st capillary of each trench holding four capillaries (in the STEC pan) and $19 \mu \mathrm{L}$ each to the two trenches holding three capillaries in the O-antigen cassette, in order to hydrate the gels with the sample. Negative control capillaries were hydrated with water. For the positive control capillaries, a known positive control sample from AAF was used. Desiccated gels inside the capillaries need about $10 \mathrm{~min}$ to hydrate.

For conventional PCR tests, $6 \mu \mathrm{L}$ of the enriched carcass swab sample was added to each reaction. For the positive and negative control PCRs, a positive control from AAF and water were used respectively. The latter confirms the sterility of the cassette.

\section{PCR and MCA}

PCR was performed on cassettes with hydrated gel capillaries in a prototype instrument explained earlier [11]. Briefly, it contains a Peltier device for heating and cooling, a laser for fluorescence excitation, and a CCD camera to acquire the images during PCR and MCA. They are controlled by a microprocessor. A laptop computer running a customized Java-based program was used to control the instrument. The DNA amplification was performed with a predenaturation step of $94{ }^{\circ} \mathrm{C}$ for $3 \mathrm{~min}$, then 35 cycles of $94{ }^{\circ} \mathrm{C}$ for $15 \mathrm{~s}, 59^{\circ} \mathrm{C}$ for $20 \mathrm{~s}$, and $72{ }^{\circ} \mathrm{C}$ for $20 \mathrm{~s}$, followed by a final amplification of $72{ }^{\circ} \mathrm{C}$ for $2 \mathrm{~min}$. Upon the completion of the PCR, MCA was performed by heating the cassette from $70^{\circ} \mathrm{C}$ to $90{ }^{\circ} \mathrm{C}$ and the $\mathrm{CCD}$ images were taken at $0.2^{\circ} \mathrm{C}$ degree intervals. They were analyzed to measure the melting temperature for amplicons in each capillary with ImageJ software (National Institutes of Health, U.S.) using the MicroArray Rectangular Plug-in (Dr Robert Dougherty, OptiNav Inc., Redmond, WA) to plot the negative derivative of the fluorescence with respect to the temperature in order to determine the melting temperature $\left(\mathrm{T}_{\mathrm{m}}\right)$ of the PCR products.

Initially the samples were tested for the presence of the four STEC genes (O157, eae, stx 1 and stx2). If the sample was pathogenic, PCR was performed with a panel of $\mathrm{O}$-antigen primer sets.

\section{Conventional PCR}

For comparison of the data obtained using cassette PCR, conventional PCR was performed on all 820 samples. Separate reaction mixes were prepared with each of the 0157, eae, stx1, and stx2 primer sets (Table 6). Each $25 \mu \mathrm{L}$ reaction mix consisted of $5 \mu \mathrm{L}$ of $5 \times \mathrm{xCR}$ buffer, $0.5 \mu \mathrm{L}$ of $50 \mathrm{mmol} / \mathrm{L} \mathrm{MgCl}_{2}, 0.5 \mu \mathrm{L}$ of $10 \mathrm{mmol} / \mathrm{L} \mathrm{dNTP}, 0.3 \mu \mathrm{L}$ of $2 \%$ bovine serum albumin, $0.5 \mu \mathrm{L}$ of $10 \mu \mathrm{M}$ primer solution for stx1 and stx2, and $1.5 \mu \mathrm{L}$ of $10 \mu \mathrm{M}$ primer solution for $\mathrm{O} 157$ and eae, $0.1 \mu \mathrm{L}$ of $20 \mathrm{U} / \mathrm{mL}$ Taq polymerase, $6 \mu \mathrm{L}$ of sample and water. Thermal cycling was performed with a pre-denaturation step of $94{ }^{\circ} \mathrm{C}$ for $3 \mathrm{~min}$, then 35 cycles of $94{ }^{\circ} \mathrm{C}$ for $20 \mathrm{~s}, 58^{\circ} \mathrm{C}$ for $30 \mathrm{~s}$, and $72{ }^{\circ} \mathrm{C}$ for $30 \mathrm{~s}$, followed by a final amplification of $72{ }^{\circ} \mathrm{C}$ for $2 \mathrm{~min}$ in a thermocycler (Applied Biosystems, Foster City, USA). PCR products were visualized in $2 \%$ agarose gels containing SYBR Safe DNA gel stain (Invitrogen, Carlsbad, USA). Only the STEC primers were tested using conventional PCR (4 tests per sample for 820 samples).

\section{Abbreviations}

AAF: Alberta Agriculture and Forestry; CCD: Charged Coupled Device; DNA: Deoxyribonucleic acid; E. coli: Escherichia coli; MCA: Melt Curve Analysis; PCR: Polymerase Chain Reaction; STEC: Shiga toxin-producing E. coli

\section{Acknowledgements}

Drs. Pilarski, Pilarski and McMullen contributed equally. We are especially grateful to Dr. Cornelia Kreplin for her advice, guidance and overall support of this project. Drs. V. Bohaychuk, N. Stashko and S. Essendoubi of the Food Safety Branch of Alberta Agriculture and Forestry are acknowledged for organizing the sample collection and providing support for experimental design. The contributions of the staff of the Agri-Food Laboratories Section, including Gary Gensler and Deana Rolheiser, are greatly appreciated for their work in preparation of enrichment broths and culture confirmation.

Authors' contributions

DPM and $J$ carried out the sample preparation and Cassette PCR experiments. DPM carried out the study design, data analysis and drafting of the manuscript. CMJ and PJW carried out the conventional PCR testing. 
DPM, LMP, PMP and LMM wrote the manuscript. All authors read and approved the final manuscript. LMP, PMP and LMM supervised the study.

\section{Funding}

This work was funded by a grant from the Agriculture Funding Consortium to PMP and LMM, with funds from Alberta Innovates BioSolutions and the Alberta Livestock and Meat Agency who equally funded the research. The funding bodies had no role in the study design, data collection, analysis, interpretation or writing of the manuscript.

\section{Availability of data and materials}

All the data required is included in the manuscript

\section{Ethics approval and consent to participate}

Not applicable.

\section{Consent for publication}

Not applicable.

\section{Competing interests}

The authors declare that they have no competing interests.

\section{Author details}

${ }^{1}$ Department of Oncology, University of Alberta and Cross Cancer Institute, 11560 University Ave, Edmonton, AB T6G 1Z2, Canada. ${ }^{2}$ Department of Agricultural, Food and Nutritional Science, University of Alberta, Edmonton, Alberta T6G 2P5, Canada. ${ }^{3}$ Division of Physical Medicine \& Rehabilitation, Department of Medicine, University of Alberta, 5-005 Katz Group Centre for Pharmacy and Health Research, Edmonton, AB T6G 2E1, Canada.

Received: 25 November 2018 Accepted: 11 July 2019

Published online: 30 July 2019

\section{References}

1. Conrad CC, Stanford K, McAllister TA, Thomas J, Reuter T. Further development of sample preparation and detection methods for 0157 and the top 6 non-O157 STEC serogroups in cattle feces. J Microbiol Methods. 2014;105:22-30.

2. Karmali MA. Emerging public health challenges of Shiga toxin-producing Escherichia coli related to changes in the pathogen, the population, and the environment. Clin Infect Dis. 2017;64(3):371-6.

3. Hunt D, Figley C, Manage DP, Lauzon J, Figley R, Pilarski LM, McMullen LM, Pilarski PM. Monitoring food pathogens: novel instrumentation for cassette PCR testing. PLoS One. 2018;13(5):e0197100.

4. Gill A, Gill CO. Non-O157 verotoxigenic Escherichia coli and beef: a Canadian perspective. Can J Vet Res. 2010;74(3):161-9.

5. Bettelheim KA. The non-0157 Shiga-toxigenic (Verocytotoxigenic) Escherichia coli; under-rated pathogens. Crit Rev Microbiol. 2007:33(1):67-87.

6. Kappeli U, Hachler H, Giezendanner N, Beutin L, Stephan R. Human infections with non-0157 Shiga toxin-producing Escherichia coli, Switzerland, 2000-2009. Emerg Infect Dis. 2011;17(2):180-5.

7. Tseng M, Sha Q, Rudrik JT, Collins J, Henderson T, Funk JA, Manning SD. Increasing incidence of non-O157 Shiga toxin-producing Escherichia coli (STEC) in Michigan and association with clinical illness. Epidemiol Infect. 2016;144(7):1394-405.

8. Elder JR, Bugarel $M$, den Bakker HC, Loneragan GH, Nightingale KK. Interrogation of single nucleotide polymorphisms in gnd provides a novel method for molecular serogrouping of clinically important Shiga toxin producing Escherichia coli (STEC) targeted by regulation in the United States, including the "big six" non-O157 STEC and STEC 0157. J Microbiol Methods. 2016;129:85-93.

9. Olavesen KK, Lindstedt BA, Lobersli I, Brandal LT. Expression of Shiga toxin 2 (Stx2) in highly virulent Stx-producing Escherichia coli (STEC) carrying different anti-terminator (q) genes. Microb Pathog. 2016;97:1-8.

10. Manage DP, Lauzon J, Zahariadis G, Pilarski LM. Storing self-contained gel capillary cassettes for POC medical diagnostics. Lab Chip. 2013; 13(20):4087-95.

11. Manage DP, Lauzon J, Atrazev A, Chavali R, Samuel RA, Chan B, Morrissey YC, Gordy W, Edwards AL, Larison K, et al. An enclosed in-gel PCR amplification cassette with multi-target, multi-sample detection for platform molecular diagnostics. Lab Chip. 2013;13(13):2576-84.
12. Manage DP, Ma L, Lauzon J, Howell A, Belch AR, Mackey JR, Pilarski LM. Genotyping single nucleotide polymorphisms with an automated and self-contained PCR cassette. J Mol Diagn. 2014;16(5):550-7.

13. Manage DP, Lauzon J, Atrazhev A, Pang XL, Pilarski LM. A novel method for sample delivery and testing of whole blood: gel strip PCR for point of care (POC) molecular diagnostics. Lab Chip. 2013;13(20):4011-4.

14. Manage DP, Pilarski LM. Miniaturized technology for DNA typing: cassette PCR. In: Bugert P, editor. Molecular Typing of Blood Cell Antigens, vol. 1310. Totowa: Humana Press Inc; 2015. p. 175-91.

15. Wittwer CT, Reed GH, Gundry CN, Vandersteen JG, Pryor RJ. High-resolution genotyping by amplicon melting analysis using LCGreen. Clin Chem. 2003; 49(6):853-60.

16. Valadez AM, Debroy C, Dudley E, Cutter CN. Multiplex PCR detection of Shiga toxin-producing Escherichia coli strains belonging to serogroups 0157 , 0103, 091, 0113, 0145, 0111, and 026 experimentally inoculated in beef carcass swabs, beef trim, and ground beef. J Food Prot. 2011;74(2):228-39.

17. Dean-Nystrom EA, Melton-Celsa AR, Pohlenz JFL, Moon HW, O'Brien AD. Comparative pathogenicity of Escherichia coli 0157 and intimin-negative non-0157 Shiga toxin-producing E. coli strains in neonatal pigs. Infect Immun. 2003;71(11):6526-33.

18. Skinner C, McMahon S, Rasooly R, Carter JM, He XH. Purification and characterization of Shiga toxin $2 \mathrm{f}$, an immunologically unrelated subtype of Shiga toxin 2. PLoS One. 2013;8(3):e59760.

19. Luna-Gierke RE, Griffin PM, Gould LH, Herman K, Bopp CA, Strockbine N, Mody RK. Outbreaks of non-O157 Shiga toxin-producing Escherichia coli infection: USA. Epidemiol Infect. 2014;142(11):2270-80.

20. Bannon J, Melebari M, Jordao C, Leon-Velarde CG, Warriner K. Incidence of top 6 Shiga toxigenic Escherichia coli within two Ontario beef processing facilities: challenges in screening and confirmation testing. Aims Microbiol. 2016;2(3):278-91.

21. Dewsbury DM, Renter DG, Shridhar PB, Noll LW, Shi XR, Nagaraja TG, Cernicchiaro N. Summer and winter prevalence of Shiga toxin producing Escherichia coli (STEC) O26, O45, 0103, 0111, 0121, 0145, and 0157 in feces of feedlot cattle. Foodborne Pathog Dis. 2015;12(8):726-32.

22. Nielsen EM, Andersen MT. Detection and characterization of verocytotoxin-producing Escherichia coli by automated 5 ' nuclease PCR assay. J Clin Microbiol. 2003;41(7):2884-93.

23. Primer and probe sequences and reagent concentrations for non-0157 Shiga toxin-producing Escherichia coli (STEC) real-time PCR assay, laboratory guidebook: MLG 5B appendix 1.01. https://www.fsisusdagov/wps/wcm/ connect//MLG_5B_Appendix_1_01pdf. Accessed 4 June 2012

24. Blais BW, Martinez-Perez A. A simple PCR-based macroarray system for detection of multiple gene markers in the identification of priority enterohemorrhagic Escherichia coli. J Food Prot. 2011;74(3):365-72.

25. Fratamico PM, Bagi LK, Cray WC, Narang N, Yan XH, Medina M, Liu YH. Detection by multiplex real-time polymerase chain reaction assays and isolation of Shiga toxin producing Escherichia coli serogroups O26, O45, 0103, 0111, 0121, and 0145 in ground beef. Foodborne Pathog Dis. 2011;8(5):601-7

26. Paddock Z, Shi XR, Bai JF, Nagaraja TG. Applicability of a multiplex PCR to detect O26, O45, O103, 0111, 0121, 0145, and 0157 serogroups of Escherichia coli in cattle feces. Vet Microbiol. 2012;156(3-4):381-8.

27. DebRoy C, Fratamico PM, Roberts E, Davis MA, Liu YH. Development of PCR assays targeting genes in O-antigen gene clusters for detection and identification of Escherichia coli $\mathrm{O} 45$ and 055 serogroups. Appl Environ Microbiol. 2005;71(8):4919-24.

\section{Publisher's Note}

Springer Nature remains neutral with regard to jurisdictional claims in published maps and institutional affiliations. 